\title{
Impact of COVID-19 pandemic on the pediatric services of a tertiary care hospital in North India: A retrospective review
}

\author{
Akriti Gera ${ }^{1}$, Amitabh Singh ${ }^{2}$, Nidhi Sungadhi ${ }^{3}$, Nidhi Aggarwal $^{4}$, Rani Gera $^{5}$ \\ From ${ }^{1}$ Senior Resident, ${ }^{2}$ Associate Professor, ${ }^{4}$ Assistant Professor, ${ }^{5}$ Professor and Head Department of Pediatrics, Vardhman Mahavir Medical College \\ and Safdarjung Hospital, New Delhi, India, ${ }^{3}$ Associate Professor, Department of Pediatrics and Surgery, Vardhman Mahavir Medical College and \\ Safdarjung Hospital, New Delhi, India
}

\begin{abstract}
Background: The novel coronavirus, severe acute respiratory syndrome coronavirus 2 (SARS-CoV-2), has affected the world at large. To control the spread of the virus, the Government of India promoted simple measures such as social distancing and hand hygiene. Yet, the most prominent one was a strict nationwide lockdown on all non-essential services and complete curtailment of the public transport. Objective: Our study aims to quantify the impact of COVID-19 pandemic and lockdown measures on the pediatric services of a tertiary care center in North India. Materials and Methods: A retrospective observational study was done to analyze the change in our outpatient visits, admissions, and number of institutional deliveries, immunization services, pediatric surgeries, and mortality rates during the lockdown period when compared to the pre-lockdown period. Data of all children aged 0-12 years who presented to the pediatric medicine and pediatric surgery departments were collected. Data were divided into two groups; January 1, 2020-March 31, 2020 and April 1, 2020-June 30, 2020. Results: There was a reduction of 79.1\% OPD attendance and 70.8\% in immunization visits. Inpatient admission in pediatrics medicine and surgery decreased by $59.8 \%$ and $67.6 \%$, respectively. The mortality rate increased from $11.8 \%$ to $13 \%$ and $7.6 \%$ to $19.6 \%$, respectively. Emergency area visits decreased by $55.3 \%$ with an increase in mortality rate from $2.4 \%$ to $6.2 \%$. Intramural births decreased by $55.4 \%$. Conclusion: The COVID-19 pandemic has led to an unmet need of pediatric services. This requires urgent management or else it may halt the progress made in different aspects of health care.
\end{abstract}

Key words: COVID-19, Pediatric, Impact, SARS-CoV-2

$\mathrm{S}$ evere acute respiratory syndrome coronavirus 2 (SARS-CoV-2) has caused a pandemic since its discovery in a wholesale food market in Wuhan city, China, in late December 2019. Epidemiological studies performed there concluded that SARS-CoV-2 was the source of the outbreak or played a role in its' initial amplification [1]. Daily increase in number of cases and deaths due to this coronavirus disease, or COVID-19, is astounding. Not only as absolute numbers [2] but also the rate of increase has left the best of us befuddled. India stands as the second worst affected nation (after the United States of America and Brazil) with a case fatality rate $2.6 \%$, much better than the global average of $4.3 \%$ [3].

India reported her first case on January 30, 2020, in Thrissur district, Kerala [4]. Subsequently, the Government of India took a number of measures to prevent rampant spread of the virus; the most notable one being a nationwide 21-day lockdown, announced

\section{Access this article online}

Received - 05 August 2020

Initial Review - 18 August 2020

Accepted - 31 August 2020

DOI: 10.32677/IJCH.2020.v07.i09.004 on March 24, 2020. Lockdown restrictions had shown to increase the doubling time of the virus in other countries $[5,6]$. It was further extended on April 14, 2020, for 19 days. Subsequently, from May 1, 2020, the nation was divided into three zones (red, orange, and green) depending on the number of active cases and the relaxations were allowed accordingly [7]. The phased removal of restrictions or unlocking was started in early June.

The initial lockdown restricted people from stepping out of their homes, other than for emergency services. All transports, air, rail, and road, were suspended. Strict check points on state borders, while necessary, caused serious hindrance. Public transport ceased within the city. Only transportation of essential goods and emergency services was permitted. As a result, patients faced great difficulty to contact their doctors and reach tertiary health centers.

While the positive effects of the lockdown on the environment have been studied [8-10], its' effect on health services remains uncertain. Hence, in this study, we analyzed the impact of the COVID-19 pandemic on pediatric services at our tertiary care hospital from January to June 2020.

Correspondence to: Dr. Rani Gera, Professor and Head, Pediatrics, Vardhman Mahavir Medical College and Safdarjung Hospital, New Delhi, India. E-mail: gera.akriti@gmail.com

(C) 2020 Creative Commons Attribution-NonCommercial 4.0 International License (CC BY-NC-ND 4.0). 


\section{MATERIALS AND METHODS}

This was a retrospective observational study conducted in one of the largest tertiary care hospitals of North India. We collected admission and mortality data from the departments of pediatrics and pediatric surgery treating neonates and children $<12$ years. Data of following areas were collected from the hospital information management system: Outpatient department (OPD), immunization clinic, inpatient department, pediatric intensive care unit (PICU), neonatal intensive care unit (NICU), and pediatric surgery wards, emergency room, labor room, and operation theater. The data were divided into two groups according to the time frame:

a. January 1,2020-March 31, 2020, depicting inflow of patients before the implementation of the lockdown.

b. April 1, 2020-June 30, 2020, representing the inflow during the lockdown.

The children who presented outside the aforementioned timeframe were excluded from the study. The month end data were collected from the different catchment areas. The data from January 1, 2020, to March 30, 2020, was added as (a). It was representative of the hospital's working before the effect of COVID-19 pandemic. The data from April 1, 2020, to June 30, 2020, was added as (b). It was representative of the impact of lockdown on hospital services. The reduction in patient inflow was calculated as: $\mathrm{a}-\mathrm{b} / \mathrm{a} \times 100$.

\section{RESULTS}

The pediatric OPD attendance fell by $79.1 \%$ in April-June 2020, when compared to January-March 2020 (Table 1). There was $70.8 \%$ decrease in immunization clinic attendance during the lockdown period. Maximum children (1313) were immunized in January, 2020. The attendance was least in April, 2020 (69 children) (Table 1). Our data shows that the admissions in pediatric medicine ward and PICU decreased by $59.8 \%$ during the lockdown period, indicating reduction from about 26 children/ day to 11 day (Table 1). There was $67.6 \%$ decline in the admission rate in the pediatric surgery ward (Table 1). Our emergency area catered to pediatric patients approximately 900 children/month from January to March 2020 . This decreased by $55.3 \%$ in the next 3 months, that is, 400 children/month.

While our inpatient mortality rate was $11.8 \%$ for the first 3 months, it increased to $13 \%$ in the next 3 months. The mortality rate among children admitted drastically rose from $7.6 \%$ to $19.6 \%$ while in the emergency area, it rose from $2.4 \%$ to $6.2 \%$ during the lockdown period (Table 2).

Despite the decrease in intramural births (55.4\%), there was no percentage change between the modes of delivery (Table 3 ).

Our data also showed a decrease in NICU admissions in the recent 3 months, from $18.8 \%$ to $14 \%$, but there was no change in increase in mortality among them.

\section{DISCUSSION}

The COVID-19 pandemic is causing insurmountable amount of stress in our lives. While the government mandated restrictions directly affected the coronavirus spread, but it also affected hospital services and other innumerous non-coronavirus diseases adversely.

This study quantifies the impact of the notable lockdown. This tertiary care hospital was one of the few centers which continued to provide services to those afflicted with coronavirus (in a separately designated area) as well as other illnesses. Some of the other pediatric centers in this region were converted to completely dedicated COVID-19 hospital, which makes the finding of our study even more puzzling.

Our study found decreased admission rates, decreased institutional deliveries, lesser number of surgeries, decreased immunization visits, and increased percentage mortality during the lockdown period. We evaluated the decrease in the number of patients presenting to our hospital during the lockdown. The decrease in OPD attendance may be explained by the restrictions on travel. Presumably, our patients sought treatment for minor ailments at a nearby health center. While 1313 children came for immunization in January 2020 to our hospital, it drastically fell 6 months later to 390 children in June 2020. About 70.8\% of children may have missed their second dose of vaccination and have gross reduction in seroconversion which may lead to outbreak of vaccine preventable diseases and increase in under-5 mortality in the foreseeable future.

As could be expected, the admission rates to the pediatric medicine ward reduced by $59.8 \%$ during the lockdown. Since elective surgeries were suspended, $67.6 \%$ reduction in the pediatric surgery ward admissions was seen. There was $55.3 \%$ reduction in emergency visits as well. However, on evaluating the mortality rates, we found $1.2 \%$ and $12 \%$ increases in the pediatric medicine and surgery cases, respectively. This could

Table 1: Admission data before and during lockdown

\begin{tabular}{lccc}
\hline Area & January 1, 2020-March 31, 2020 & April 1, 2020-June 30, 2020 & Percentage decrease \\
\hline Outpatient department & 20,978 & 4354 & $79.1 \%$ \\
Immunization clinic & 2725 & 797 & $70.8 \%$ \\
Inpatient & & & $59.8 \%$ \\
$\quad$ Pediatric medicine & 2552 & 1025 & $67.6 \%$ \\
$\quad$ Pediatric surgery & 550 & 178 & $55.3 \%$ \\
Emergency (pediatric medicine + & 2748 & 1227 & $44.6 \%$ \\
pediatric surgery) & 5487 & 2448 & \\
Intramural births & & & \\
\hline
\end{tabular}


Table 2: Admission and mortality data before and during lockdown

\begin{tabular}{|c|c|c|c|c|c|c|}
\hline \multirow[t]{2}{*}{ Area } & \multicolumn{3}{|c|}{ January 1, 2020-March 31, 2020} & \multicolumn{3}{|c|}{ April 1, 2020-June 30, 2020} \\
\hline & Admission & Death & Percentage & Admission & Death & Percentage \\
\hline \multicolumn{7}{|l|}{ Inpatient department } \\
\hline Pediatric medicine & 2552 & 301 & $11.8 \%$ & 1025 & 134 & $13.0 \%$ \\
\hline Pediatric surgery & 550 & 42 & $7.6 \%$ & 178 & 35 & $19.6 \%$ \\
\hline Emergency services (pediatric medicine + pediatric surgery) & 2748 & 66 & $2.4 \%$ & 1227 & 77 & $6.2 \%$ \\
\hline
\end{tabular}

Table 3: Intramural births and mode of delivery before and during lockdown

\begin{tabular}{|c|c|c|c|}
\hline Area & January 1, 2020-March 31, 2020 & April 1, 2020-June 30, 2020 & Percentage decrease \\
\hline Number of deliveries & 5671 & 2544 & $55.1 \%$ \\
\hline Number of live births & 5487 & 2448 & $55.4 \%$ \\
\hline $\begin{array}{l}\text { Mode of delivery } \\
\text { Vaginal ( } \pm \text { Assistance) ( } \% \text { of live births) } \\
\text { Cesarean section ( } \% \text { of live births) }\end{array}$ & $\begin{array}{l}3913(71.3 \%) \\
1574(28.7 \%)\end{array}$ & $\begin{array}{c}1744(71.2 \%) \\
704(28.7 \%)\end{array}$ & \\
\hline
\end{tabular}

be explained as children could not manage to reach a tertiary health-care facility easily due to restricted public transport and the escalated cost of travel. From April to June, 2020, only emergency surgeries were being performed on grave direful cases requiring immediate interventions, which may have contributed to the increase in mortality rate. Aerosol-generating procedures which have high risk of infections were avoided; hence, surgeries took longer than usual.

Intramural births fell by $44.6 \%$ in the past 3 months. This could be due to travel restrictions and fear amongst the public regarding increased risk of exposure to the virus in the hospital. There is also a lot of apprehension surrounding being tested for the coronavirus on admission. If tested positive for COVID-19, giving birth in isolation would also lead to increase rate of postpartum depression and disrupted motherinfant bonding [11].

Public health has made tremendous progress in decreasing the negative health indicators, such as under-5 and infant mortality, and controlling vaccine preventable diseases. The gross unmet need of pediatric services during the lockdown, as highlighted in this study, may undo that hard work.

We must actively trace the children who have missed their due vaccinations, with the help of their birth records. District health centres should be strengthened with adequate personnel to continue follow-up of chronic cases such as tuberculosis or controlled epilepsy and ensure treatment compliance, monitor toxicities, and/or inadequate dosage. Children afflicted with diseases which cannot be managed at a peripheral institute and require regular follow-up for medications, such as malignancies, should be allowed a safe and easy passage to a tertiary health centre. As our patients find their way back to our OPD, we should advice on how to improve mental health $[12,13]$ and decrease risk of obesity [14] (secondary to lack of activities). Children with attention deficit disorder (ADHD)/obsessive compulsive disorder (OCD) [15] and chronic neuromuscular disorders would have faced a disruption in their schedule, regressing the controls achieved.

Our study has few limitations. First, we have evaluated the change in services for a short duration of time, i.e. during lockdown period. Although even after the lockdown has been lifted, all health services have not resumed. Second, data could have been compared for the same months of the previous year. Few months have higher patient inflow due to seasonal presentation of diseases. Third, admission and mortality data of all departments and other hospitals may be able to give a more wholesome picture of the impact of the lockdown on health services.

\section{CONCLUSION}

The lockdown implemented due to COVID-19 caused difficulty for the public in accessing medical services. Large unmet need of pediatric services would cause challenges in the foreseeable future. Various child health indicators are likely to be adversely affected by the COVID-19 pandemic which may negate the gains made in various health programs.

\section{REFERENCES}

1. WHO. Coronavirus Disease 2019 (COVID-19) Situation Report-94; 2020. Available from: https:/www.who.int/docs/default-source/coronaviruse/ situation-reports/20200423-sitrep-94-covid-19.pdf. [Last accessed on 2020 Jul 16].

2. WHO Coronavirus Disease (COVID-19) Dashboard; 2020. Available from: https://www.covid19.who.int. [Last accessed on 2020 Jul 16].

3. India Fights Corona COVID-19; 2020. Available from: https://www.mygov. in/covid-19. [Last accessed on 2020 Jul 16].

4. India's First Coronavirus Infection Confirmed in Kerala. Available from: https:/www.thehindu.com/news/national/indias-first-coronavirus-infectionconfirmed-in-kerala/article30691004.ece. [Last accessed on 2020 Jul 16].

5. Lau H, Khosrawipour V, Kocbach P, Mikolajczyk A, Schubert J, Bania J, et al. The positive impact of lockdown in Wuhan on containing the COVID-19 outbreak in China. J Travel Med 2020;27:taaa037.

6. Moris D, Schizas D. Lockdown during COVID-19: The Greek success. In Vivo 2020;34 Suppl 3:1695-99.

7. Ministry of Home Affairs, Government of India. To Extend Lockdown Period for 2 Weeks W.E.F. 4.5. 2020 with New Guidelines Order Number 40-3/3030-DM-I(A). New Delhi: Ministry of Home Affairs; 2020.

8. Paital B, Das K, Parida S. Inter nation social lockdown versus medical care against COVID-19, a mild environmental insight with special reference to India. Sci Total Environ 2020;728:138914.

9. Muhammad S, Long X, Salman M. COVID-19 pandemic and environmental pollution: A blessing in disguise? Sci Total Environ 2020;728:138820. 
10. Nakada L, Urban R. COVID-19 pandemic: Impacts on the air quality during the partial lockdown in São Paulo state, Brazil. Sci Total Environ 2020;730:139087.

11. Viaux S, Maurice P, Cohen D, Jouannic J. Giving birth under lockdown during the COVID-19 epidemic. J Gynecol Obstet Hum Reprod 2020;49:101785.

12. Mental Health and Psychosocial Considerations during the COVID-19 Outbreak; 2020. Available from: https://www.apps.who.int/iris/bitstream/ handle/10665/331490/who-2019-ncov-mentalhealth-2020.1-eng.pdf. [Last accessed on $2020 \mathrm{Jul} 17]$.

13. Psycho-Social Experiences of Youths during the COVID-19 Lockdown: Insights from Harare, Zimbabwe; 2020. Available from: http://www.beman. ase.ro/special_issue_1/4.pdf. [Last accessed on 2020 Jul 17].

14. di Renzo L, Gualtieri P, Pivari F, Soldati L, Attinà A, Cinelli G, et al. Eating habits and lifestyle changes during COVID-19 lockdown: An Italian survey. J Transl Med 2020;18:229.

15. Renata MS, Roseli GS, Daniel LC. Obsessive-compulsive disorder during the COVID-19 pandemic. Braz J Psychiatry 2020;1;1.

Funding: Departmental; Conflicts of Interest: None Stated.

How to cite this article: Gera A, Singh A, Sungadhi N, Aggarwal N, Gera R. Impact of COVID-19 pandemic on the pediatric services of a tertiary care hospital in North India: A retrospective review. Indian J Child Health. 2020; 7(9):371-374. 